\title{
Volatilização de amônia em pastagem adubada com fontes nitrogenadas
}

\section{Paulo Henrique Menezes das Chagas ${ }^{1}$, Geraldo Candido Cabral Gouveia ${ }^{2}$, Geany Giovana Silva da Costa $^{3}$, Willams Ferreira Sousa Barbosa ${ }^{3}$, Ana Carolina Alves ${ }^{3}$}

\author{
${ }^{1}$ Universidade Federal de Mato Grosso do Sul (UFMS), Campus Chapadão do Sul, Chapadão do Sul, Mato Grosso do Sul, Brasil. E- \\ mail: paulochagas92@gmail.com \\ ${ }^{2}$ Universidade Estadual Paulista (UNESP), Campus Ilha Solteira, Ilha Solteira, São Paulo, Brasil. E-mail: \\ geraldocgouveia@hotmail.com \\ ${ }^{3}$ Universidade Estadual de Mato Grosso do Sul (UEMS), Campus Cassilândia, Cassilândia, Mato Grosso do Sul, Brasil. E-mail: \\ geanys.costa@hotmail.com,willams93@hotmail.com, anacarolina@uems.br
}

Recebido: 30/10/2016; Aceito: 21/05/2017

\begin{abstract}
RESUMO
A adubação nitrogenada é essencial para o aumento de produção de forrageiras, porém a fonte de nitrogênio (N) e fatores como o manejo podem ocasionar elevadas perdas de amônia $\left(\mathrm{NH}_{3}\right)$ por volatilização. $\mathrm{O}$ presente trabalho foi conduzido com objetivo de quantificar as perdas de $\mathrm{N}$ por volatilização de $\mathrm{NH}_{3}$ em fontes nitrogenadas em pastagem. O experimento foi desenvolvido na Universidade Estadual de Mato Grosso do Sul (UEMS), Unidade Universitária de Cassilândia-MS, utilizando o delineamento experimental em blocos ao acaso com quatro tratamentos (ureia; ureia revestida com polímero; ureia com inibidor de urease; e nitrato de amônia) e cinco repetições. Em todos os tratamentos foi aplicada a dose equivalente a $100 \mathrm{~kg} \mathrm{ha}^{-1} \mathrm{de} \mathrm{N}$. Para a quantificação da volatilização de $\mathrm{N}-\mathrm{NH}_{3}$ foram utilizados absorvedores de espumas, colocados à $1,0 \mathrm{~cm}$ da superfície do solo. As perdas de $\mathrm{N}-\mathrm{NH}_{3}$ por volatilização foram menores quando utilizou-se ureia com inibidor de urease [N-(n-butil) tiofosfórico triamida] e ureia com polímero, quando comparadas ao uso da ureia convencional. A ureia com NBPT retardou o pico de volatilização em dois dias em relação à ureia convencional.
\end{abstract}

Palavras-chave: forrageira, Urochloa, $\mathrm{NH}_{3}$, ureia.

\section{Volatilization of ammonia in pasture fertilized with nitrogen sources}

\begin{abstract}
Nitrogen fertilization is essential for increasing tropical forage production, however, the nitrogen $(\mathrm{N})$ source and factors as management used can cause high ammonia $\left(\mathrm{NH}_{3}\right)$ losses for volatilization. The present work was conducted with objective to quantify $\mathrm{N}$ losses by $\mathrm{NH}_{3}$ volatilization of nitrogen sources in pasture area. The experiment was developed at the State University of Mato Grosso do Sul (UEMS), in Cassilândia, MS, Brazil using the experimental design in randomized blocks with four treatments (urea; urea coated with polymer; urea treated with NBPT; and, ammonium nitrate) and five repetitions. Being applied at dosage equivalent to $100 \mathrm{~kg}$ ha ${ }^{1}$ of $\mathrm{N}$. For quantification of volatilization $\mathrm{NH}_{3}$ were used absorbing foams, placed $1.0 \mathrm{~cm}$ from the soil surface. Losses of $\mathrm{NH}_{3}$ volatilization were lower when urea treated with NBPT (N-(n-butil) tiofosfórico triamida) and urea coated with polymer when compared to the use of conventional urea. The urea treated with NBPT delayed the peak volatilization in two days in relation to other sources.
\end{abstract}

Key words: forage, Urochloa, $\mathrm{NH}_{3}$, urea. 


\section{Introdução}

Em decorrência dos altos custos dos alimentos concentrados para alimentação animal, o produtor utiliza as pastagens, principalmente por ser o alimento mais barato disponível. Quando manejado corretamente fornece quantidades de nutrientes suficiente para o desenvolvimento do animal; aproximadamente $85 \%$ das novas áreas de gramíneas implantadas no Brasil estão utilizando o gênero Urochloa (SANTOS et al., 2009).

Apesar da importância das pastagens para a pecuária, ainda, não se utiliza a adubação de forma adequada, fazendo com que as pastagens não alcancem todo o seu potencial de desenvolvimento, e ao passar dos anos perdem qualidade e produtividade (BENETT et al., 2008). Em consequência pode ocorrer a degradação da pastagem que é um processo de perda de vigor e consequente perda de produção e qualidade (FERREIRA et al, 2010).

A ureia atualmente é o fertilizante nitrogenado mais utilizado no Brasil e no mundo, correspondendo a cerca de $60 \%$ dos fertilizantes comercializados, fato que deve às vantagens oferecidas como facilidade na fabricação, baixo custo na produção, e maior concentração de N. A falta de precipitação acompanhada de altas temperaturas após a adubação nitrogenada, propicia grandes perdas de $\mathrm{NH}_{3}$, causando aumento da volatilização acumulada (MARTHA-JUNIOR et al., 2004).

Novas fontes nitrogenadas estão sendo utilizadas a fim de evitar perdas de $\mathrm{N}$ por volatilização. $\mathrm{O}$ uso de ureia revestida por uma ou mais camadas protetoras com polímero possui liberação controlada. Os polímeros ou resinas são permeáveis à água e regulam o processo de liberação do nutriente contido no interior das camadas protetoras (SILVA et al., 2012); a mistura com NBPT (tiofosfato de N-Butiltriamida) reduz a velocidade da hidrólise da ureia, fazendo com que diminua a ação da urease (TASCA et al., 2011).
Objetivou-se com esse trabalho quantificar a perda de $\mathrm{N}$ por volatilização de $\mathrm{NH}_{3}$ de diferentes fontes de nitrogênio aplicadas em pastagem de Urochloa brizantha cv. Marandu.

\section{Material e Métodos}

$\mathrm{O}$ experimento foi realizado numa área estabelecida de Urochloa brizantha cv. Marandu, pertencente à Universidade Estadual de Mato Grosso do Sul (UEMS), em Cassilândia/MS $\left(19^{\circ} 05^{\prime} \mathrm{S}, 51^{\circ} 48^{\prime} \mathrm{W}\right.$ e altitude de $510 \mathrm{~m}$ ). De acordo com a classificação climática de Köppen, apresenta clima tropical chuvoso (Aw). O solo da área experimental é classificado como Neossolo Quartzarênico. A calagem foi realizada três meses antes do inicio das avaliações de acordo com as seguintes características químicas na camada superficial ( 0 a 20 cm): $\mathrm{pH} \mathrm{CaCl}=4,8$; matéria orgânica $=14 \mathrm{~g} \mathrm{dm}^{-3} ; \mathrm{P}$ resina $=2 \mathrm{mg} \mathrm{dm}^{-3} ; \mathrm{K}=1,4 \mathrm{mmol}_{\mathrm{c}} \mathrm{dm}^{-3} ; \mathrm{Ca}=9 \mathrm{mmol}_{\mathrm{c}}$ $\mathrm{dm}^{-3} ; \mathrm{Mg}=7,0 \mathrm{mmol}_{\mathrm{c}} \mathrm{dm}^{-3} ; \mathrm{S}=1 \mathrm{mg} \mathrm{dm}{ }^{-3} ; \mathrm{B}=0,09$ $\mathrm{mg} \mathrm{dm}^{-3} ; \mathrm{Fe}=8 \mathrm{mg} \mathrm{dm}^{-3} ; \mathrm{Mn}=8,1 \mathrm{mg} \mathrm{dm}^{-3} ; \mathrm{Zn}=0,2$ $\mathrm{mg} \mathrm{dm}{ }^{-3} ; \mathrm{Cu}=0,3 \mathrm{mg} \mathrm{dm}^{-3} ; \mathrm{Al}=2 \mathrm{mmol}_{\mathrm{c}} \mathrm{dm}^{-3} ; \mathrm{CTC}=$ $39,4 \mathrm{mmol}_{\mathrm{c}} \mathrm{dm}^{-3}$ e $\mathrm{V} \%=44$.

Os tratamentos consistiram em quatro fertilizantes nitrogenados, sendo ureia convencional (UC), ureia protegida com polímero (UP), ureia com inibidor de uréase (NBPT) e nitrato de amônio (NA), aplicados em dose de $100 \mathrm{~kg} \mathrm{ha}^{-1}$ de $\mathrm{N}$ a lanço, em uma única ocasião sobre a superfície do solo. O delineamento experimental foi em blocos ao acaso, com cinco repetições, antes do início do período de avaliações, todas as parcelas tiveram as touceiras submetidas ao corte de uniformização a $20 \mathrm{~cm}$ do solo. As temperaturas máximas, mínimas e precipitação estão representadas a seguir na Figura 1.

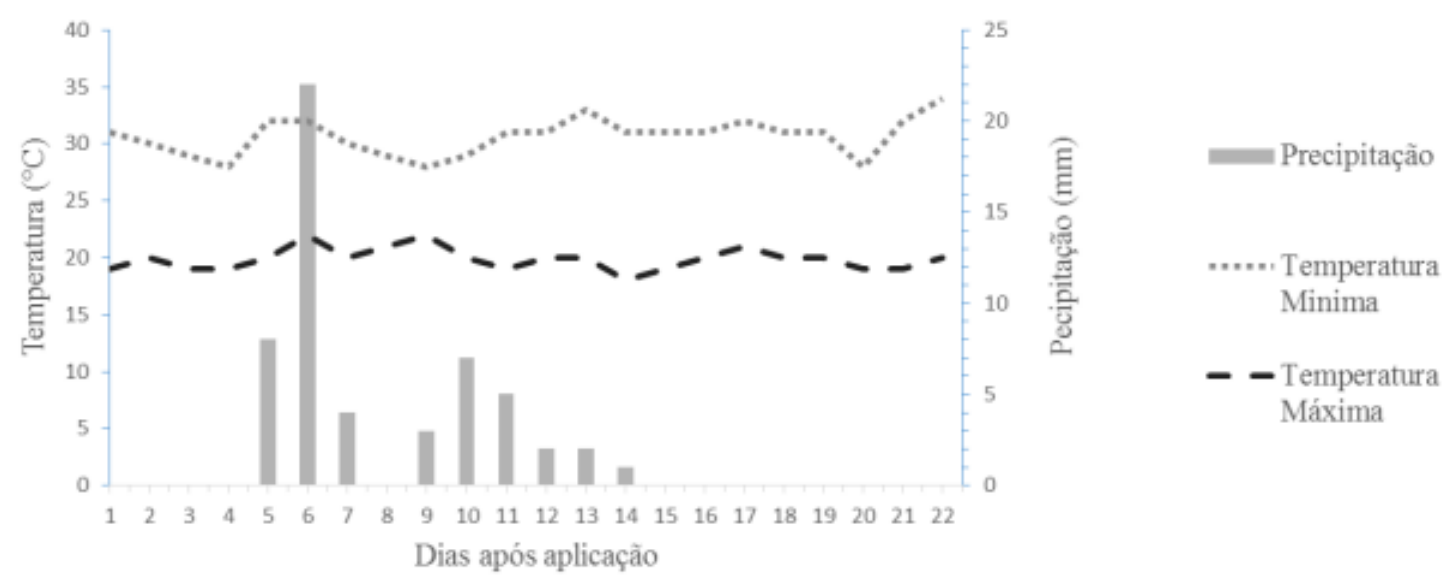

Figura 1. Temperaturas $\left({ }^{\circ} \mathrm{C}\right)$ mínima, máxima e precipitação durante o período de avaliações do experimento, os dados foram retirados do Instituto Nacional de Meteorologia (Inmet) que possui uma base próxima ao local do experimento. 
Foram utilizados absorvedores de espumas para quantificar a volatilização de $\mathrm{N}-\mathrm{NH}_{3}$, semelhantes aos usados por Trivelin e Manzoni (2002), a $1 \mathrm{~cm}$ acima do solo, utilizando espumas com tamanho de $8,0 \times 8,0 \mathrm{~cm}$, densidade de $0,02 \mathrm{~g} \mathrm{~cm}^{-3}$ que foram embebidas com 11 $\mathrm{mL}$ de ácido fosfórico $(0,05 \mathrm{~N})$ com $5 \%$ de glicerina e colocadas sobre placas de PVC com dimensão de $10 \mathrm{x}$ $10 \mathrm{~cm}$, envolvida por uma camada de fita de polytetrafluoretileno (OLIVEIRA et al., 2008).

Os absorvedores de espumas foram trocados todos os dias durante a primeira semana, após esse período foram trocados a cada dois dias até o $21^{\circ}$ dia, sendo realizadas 14 amostragens num período de 21 dias. As amostras coletadas eram acondicionadas em um freezer de modo que pudessem ser conservadas em baixa temperatura.

Para a determinação da quantidade de nitrogênio (N), as espumas foram lavadas com $300 \mathrm{~mL}$ de água deionizada em um funil de Buckner com placa porosa ligado a uma bomba de vácuo, sendo retirada uma alíquota de $50 \mathrm{~mL}$. Posteriormente a amostra era submetida à análise de nitrogênio pelo método de macrokjeldahl (AOAC, 1990), sendo para isso, adicionados $15 \mathrm{~mL}$ de $\mathrm{NaOH}(40 \%)$ à amostra para realizar a destilação e utilizada uma solução receptora com 5\% de ácido bórico e ácido clorídrico a 0,02N para a titulação.

Os dados foram submetidos à análise de variância e as médias comparadas pelo teste Tukey, a $5 \%$ de probabilidade. As análises estatísticas foram realizadas utilizando programa estatístico SISVAR 5.6 (FERREIRA, 2010).

\section{Resultados e Discussão}

A ureia convencional (UC) e a ureia protegida por polímero (UP) alcançaram o pico de volatilização de NH3 no quinto dia, já para a ureia com inibidor de uréase (NBPT) o pico ocorreu no sétimo dia (Figura 2). O NBPT pôde inibir a hidrólise da ureia por períodos de 3 a 14 dias, dependendo da temperatura do solo e condições ambientais (CANTARELLA et al., 2008).

A rápida volatilização acontece devido à rápida dissolução e hidrólise da ureia (BLACK et al., 1987). Como a precipitação ocorreu somente cinco dias após a aplicação da ureia, não houve a incorporação do fertilizante, favorecendo a volatilização. A incorporação reduz as perdas por volatilização pois aumenta o contato entre o fertilizante e as partículas do solo, aumentando a adsorção de $\mathrm{NH}_{4}$, às cargas negativas da fase sólida do solo, dificultando sua transformação para $\mathrm{NH}_{3}$ (SANGOI et al., 2003).

De acordo com Rojas et al. (2012), as maiores taxas de volatilização no sistema plantio direto ocorrem nos primeiros cinco dias após a aplicação da ureia e são altamente influenciadas pelo volume de chuvas nesse período.

Pereira et al. (2009) em trabalho realizado com diferentes fontes de ureia na cultura do milho safrinha, sob sistema de plantio direto em dois parcelamentos, sendo o primeiro durante o período mais seco e o segundo no período úmido, observaram que o pico de volatilização de $\mathrm{NH}_{3}$ ocorreu no $2^{\circ}$ e $4^{\circ}$ dia e $4^{\circ}$ e $5^{\circ}$ dia, respectivamente após aplicação dos fertilizantes nitrogenados; os tratamentos utilizando ureia revestida com polímero e ureia com inibidor de uréase reduziram a volatilização de $\mathrm{N}$ em torno de $50 \%$ em relação a ureia convencional. Segundo Zavaschi et al. (2014) ao avaliarem o efeito da aplicação de ureia convencional e ureia revestida com polímero em cobertura na cultura do milho em sistema de plantio direto, verificaram que o pico de volatilização ocorreu após o $15^{\circ}$ dia para as duas fontes, e a ureia revestida de polímero apresentou redução de perdas de $\mathrm{NH}_{3}$ por volatilização, quando comparada à ureia convencional.

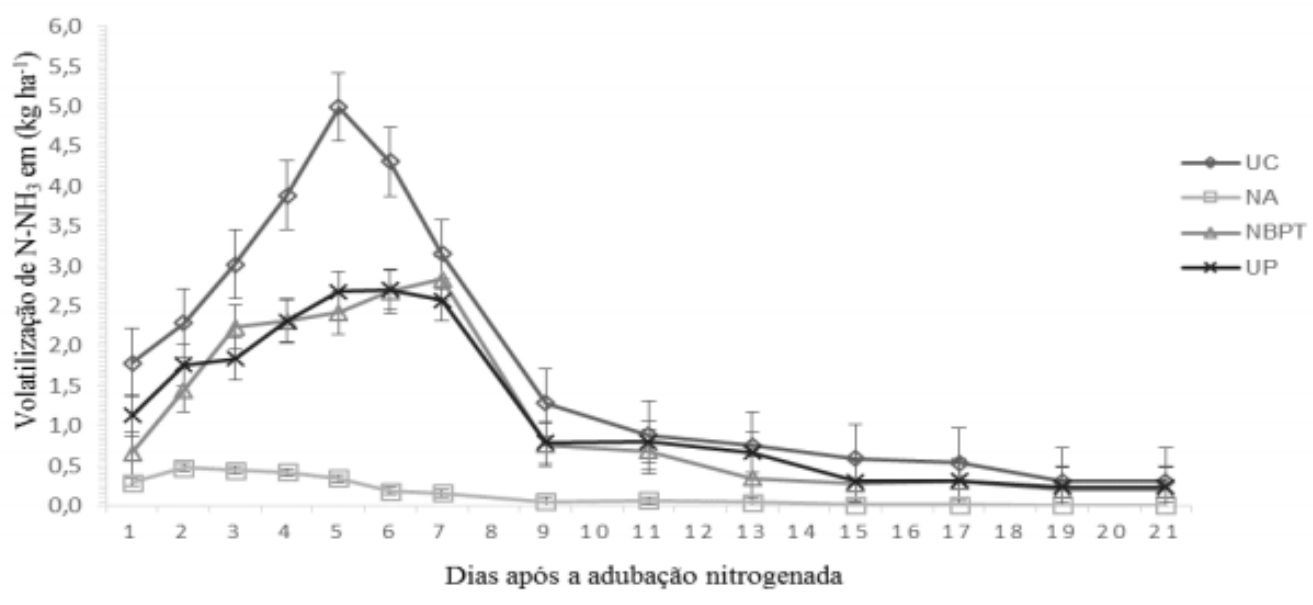

Figura 2. Perda por volatilização de $\mathrm{N}_{-} \mathrm{NH}_{3}$, após a aplicação das fontes de nitrogênio: Ureia convencional (UC), nitrato de amônio (NA), ureia com inibidor de uréase (NBPT), ureia revestida com polímero (UP). 
As perdas por volatilização de $\mathrm{N}^{-\mathrm{NH}_{3}}$ do solo iniciaram após o primeiro dia da aplicação em cobertura das fontes nitrogenadas, sendo que o NA obteve as menores perdas de $\mathrm{N}-\mathrm{NH}_{3}$ acumulado, totalizando 2,5\% de $\mathrm{N}$ volatilizado (Figura 3); resultado esperado sendo uma fonte que contém um radical nítrico e outro amoniacal, sofrendo menor perda por volatilização e acidificando menos o solo, quando comparado aos demais fertilizantes nitrogenados.

A ureia convencional obteve as maiores taxas de volatilização, tendo o total volatilizado de $28,1 \%$, sendo um valor superior quando comparado à UP e NBPT, que apresentaram perdas de 18,3 e $17,3 \%$, respectivamente.

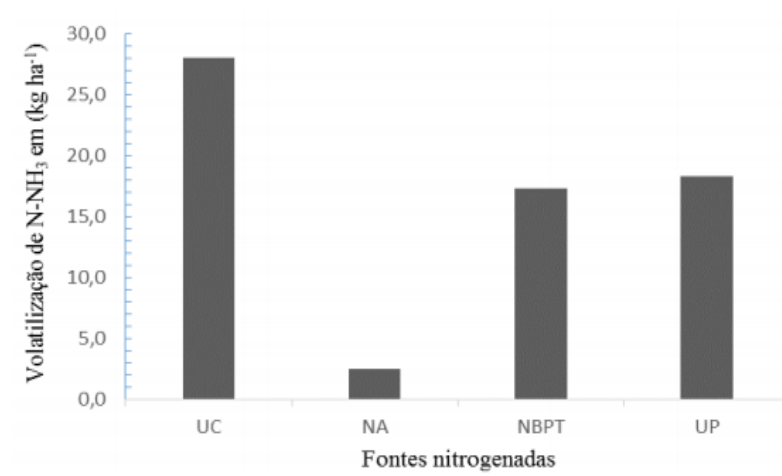

Figura 3. Volatilização total de $\mathrm{N}-\mathrm{NH}_{3}\left(\mathrm{~kg} \mathrm{ha}^{-1}\right)$ das fontes: ureia convencional (UC), nitrato de amônio (NA), ureia revestida com polímero (UP) e ureia tratada com inibidor de uréase (NBPT).

Cantarella et al. (2008) ao realizarem aplicação em superfície da ureia convencional, nitrato de amônio e ureia com NBPT na cultura da cana-de-açúcar com restos de palhada em superfície, observaram que a ureia com NBPT apresentou reduções de 15 a $78 \%$ nas perdas por volatilização da dose aplicada. Já a ureia convencional apresentou maiores perdas quando comparadas com a ureia com NBPT e com nitrato de amônio onde as perdas foram irrelevantes

\section{Conclusões}

As perdas de $\mathrm{N}-\mathrm{NH}_{3}$ por volatilização foram menores quando utilizada ureia com NBPT e ureia com polímero, se comparadas ao uso da ureia convencional.

A ureia com inibidor de urease (NBPT) retardou o pico de volatilização em dois dias em relação à ureia convencional.

$\mathrm{O}$ nitrato de amônio apresentou menores perdas de $\mathrm{N}-\mathrm{NH}_{3}$ em relação às fontes nitrogenadas utilizadas.

\section{Referências Bibliográficas}

AOAC. ASSOCIATION OF OFFICIAL ANALYTICAL CHEMISTS. Official methods of analysis of the Association of Official Analytical Chemists. 15. ed. Arlington: AOAC, 1990. 1117 p.

BENETT, C. G. S.; BUZETTI, S.; SILVA, K. S.; BERGAMASCHINE, A. F.; FABRICIO, J. A. Produtividade e composição bromatológica do capim marandu a fontes e doses de nitrogênio. Ciência e Agrotecnologia, Lavras-MG, v. $32, \quad$ n. 5 , p. 1629-1636, 2008. Disponível em <http://www.scielo.br/scielo.php?script=sci_arttext\&pid=S14 13-70542008000500041\&lng=en\&nrm=iso $>$. Acesso em 11 jun. 2016.

BLACK, A. S.; SHEROLOCK, R. R.; SMITH, N. P. Effect of timing of simulated raninfallon ammonia volatilisation from urea applied to soil of varying moisture content. Journal of Soil Science, Oxford, v. 38, n. 4, p. 679-688, 1987.

CANTARELlA, H.; TRIVELIM, P. C. O.; CONTIN, T. L. M.; DIAS, F. L. F.; ROSSETTO, R.; MARCELINO, R.; COIMBRA, R. B. \& QUAGGIO, J. A. Ammonia volatilisation from urease inhibitor-treated urea applied to sugar cane trash blankets. Scientia Agricola, Piracicaba-SP, v. 65, n. 4, p. 397-401, 2008. Disponível em <http://www.scielo.br/scielo.php?script=sci_arttext\&pid=S01 $0390162008000400011 \& \operatorname{lng}=\mathrm{en} \& \mathrm{nrm}=\mathrm{iso}>$. Acesso em 15 jun. 2016.

FERREIRA, D. F. SISVAR - Sistema de análise de variância. Versão 5.3. Lavras-MG: UFLA, 2010.

FERREIRA, R. R. M.; FILHO, J. T.; FERREIRA, V. M. Efeitos de sistemas de manejo de pastagens nas propriedades físicas do solo. Semina: Ciências Agrárias, Londrina-PR, v. 31, n. 4, p. 913-932, 2010. <Disponível em http://www.uel.br/revistas/uel/index.php/semagrarias/article/vi ew/7597/6687>. Acesso em 02 mai. 2017.

MARTHA JUNIOR, G. B.; CORSI, M.; TRIVELIN, P. C. O.; VILELA, L. PINTO, T. L. F.; TEIXEIRA, G. M.; MANZONI, C. S.; BARIONI, L. G. Perda de amônia por volatilização em pastagem de capim-tanzânia adubada com uréia no verão. Revista Brasileira de Zootecnia. Viçosa-MG, v. 33, n. 6, supl. 3, p. 2240-2247, 2004. Disponivel em <http://www.scielo.br/scielo.php?script=sci_arttext\&pid=S15 $1635982004000900009 \& \operatorname{lng}=$ en\&nrm=iso $>$. Acesso em 11 jun. 2016.

OLIVEIRA, P. P. A.; TRIVELIN, P. C. O., ALVES, A. C.; LUZ, P. H. C, HERLING, V. R. Métodos para avaliar as perdas de nitrogenio por volatilização da superficie do solo e por emissão de amônia pela folhagem de Brachiaria brizantha cv. Marandu. São Carlos - SP: Embrapa Pecuária Sudeste, 2008. 41 p. (Boletim de Pesquisa e Desenvolvimento, 16).

PEREIRA, H. S.; LEAO, A. F.; VERGINASSI, A.; CARNEIRO, M. A. C. Ammonia volatilization of urea in the out-of-seasoncorn. Revista Brasileira de Ciência do Solo, Viçosa-MG, v. 33, n. 6, p. 1685-1694, 2009. Disponivel em < http://www.scielo.br/pdf/rbcs/v33n6/a17v33n6.pdf>. Acesso em 15 jun. 2016.

ROJAS, C. A. L.; BAYER, C.; FONTOURA, S. M. V.; WEBER, M. A.; VIEIRO F. Volatilização de amônia da ureia alterada por sistemas de preparo de solo e plantas de cobertura invernais no Centro-Sul do Paraná. Revista Brasileira de Ciência do Solo, Viçosa-MG, v. 36, n. 1, p. 261-270, 2012. Disponível 
<http://www.scielo.br/scielo.php?script=sci_arttext\&pid=S01 $0006832012000100027 \& \operatorname{lng}=\mathrm{en} \& n r m=i s o>$. Acesso em 11 jun. 2016.

SANGOI, L.; ERNANI, P. R.; LECH, V. A.; RAMPAZZO, C. Volatilização de $\mathrm{N}^{-\mathrm{NH}_{3}}$ em decorrência da forma de aplicação de uréia, manejo de resíduos e tipo de solo, em laboratório. Ciência Rural, Santa Maria-RS, v. 33, n. 4, p. 687-692, 2003. Disponível em <http://www.scielo.br/scielo.php?script=sci_arttext\&pid=S01 0384782003000400016\&lng=en\&nrm=iso>. Acesso em 12 jun. 2016.

SANTOS, L. C.; BONOMO, P.; SILVA, V. B.; PATÊS, N. M. S.; SILVA, C. C. F.; PIRES, A, J, V. Características morfogênicas de Braquiárias em resposta a diferentes adubações. Acta Scientiarium, Maringá-PR, v. 31, n. 2, p. 221-226, 2009.

SILVA, A. A.; SILVA, T. S.; VASCONCELOS, A. C. P.; LANA, R. M. Q. Aplicação de diferentes fontes de ureia de liberação gradual na cultura do milho. Bioscience Journal, Uberlândia-MG, v. 28, p. 104-111, 2012.
TASCA, F. A.; ERNANI, P. R.; ROGERI, D. A.; GATIBONI, L. C.; CASSOL, P. C. Volatilização de amônia do solo após a aplicação de uréia convencional ou com inibidor de urease. Revista Brasileira de Ciência do Solo, Viçosa-MG, v. 35, n. 2, p. 493-502, 2011. Disponível em <http:// http://www.scielo.br/pdf/rbcs/v35n2/v35n2a18.pdf $>$. Acesso em: 12 jun. 2016

TRIVELIN, P. C. O.; MANZONI, C. S. Determinação de Namônia volatilizado do solo pelo método da difusão. Piracicaba-SP: Centro de Energia Nuclear na Agricultura, 2002. 11p.

ZAVASCHI, E.; FARIA, L. A.; VITTI, G. C.; NASCIMENTO, C. A. C.; MOURA, T. A.; VALE, D. W.; MENDES, F. L.; KAMOGAWA, M. Y. Ammonia volatilization and yield components after application of polymercoated urea to maize. Revista Brasileira de Ciência do Solo, Viçosa-MG, v. 38, n. 4, p. 1200-1206, 2014. Disponível em <http://www.scielo.br/scielo.php?script=sci_arttext\&pid=S01 $0006832014000400016 \& \operatorname{lng}=\mathrm{en} \& \mathrm{nrm}=\mathrm{iso}>$. Acesso em: 15 jun. 2016. 